\title{
EFFECT OF NANOCLAY-TREATED UF RESIN ON THE PHYSICAL AND MECHANICAL PROPERTIES OF PLYWOOD MANUFACTURED WITH WOOD FROM TROPICAL FAST GROWTH PLANTATIONS
}

Freddy Muñoz ${ }^{1, \star}$, Roger Moya ${ }^{1}$

\begin{abstract}
Physical and mechanical properties were evaluated on cross-laminated panels (plywood) fabricated with three plantation species (Cordia alliodora, Gmelina arborea and Vochysia ferruginea) from tropical climates in Costa Rica. The panels were glued with urea-formaldehyde resin modified with nanoclay at four concentrations $(0,75 ; 1,00 ; 1,50$ and $2,00 \%)$ and unmodified resin. It was determined that addition of nanoclay to urea-formaldehyde adhesive positively decreased moisture absorption and swelling of the plywood panel with statistical significance. However, nano-modification did not have a significant effect on the density and specific weight of plywood. Nano-modification of ureaformaldehyde resin with nanoclay at $0,75 \%$ improved the Module of rupture and Modulus of elasticity in flexure parallel to surface in the three species, also increasing mechanical resistance to strains in parallel tension, shear and compression. By means of electronic microscopy, it was evidenced that the nano-modified adhesive became diffused at the inside of the cellular structure of wood in a better way, allowing for the generation of a transition zone that increased the mechanical properties at the macro level. According to the properties evaluated, it was determined that $0,75 \%$ is the optimal percentage to use of nanoclay on urea-formaldehyde resin.
\end{abstract}

Keywords: Adhesives, Cordia alliodora, Gmelina arborea, veneers, Vochysia ferruginea.

\section{INTRODUCTION}

Cross-laminated panels of the plywood type are wood derivatives made with an odd number of veneers, each with their fibres perpendicular to the other. The veneers oriented along the fibres equate tension, reduce ruptures and minimise dimensional change and warping of the panel (Bodig and Jayne 1993). This technology makes it possible to obtain a product with good stability and mechanical strength. Resistance and rigidity of the plywood depend on the raw material, the manufacturing process, adhesive employed and conditions of use of the panel (Tenorio et al. 2011, Tenorio et al. 2012, Bayatkashkoli and Faegh 2014).

The role of bonding the various veneers with adhesive has relevance in the mechanical performance of the plywood panel. According to Frihart and Hunt (2010), an important contribution of adhesives is that they transfer and distribute strains among the veneers, increasing strength and rigidity of the plywood panels. The adhesion properties of veneers are essentially similar to those of solid wood; however, plywood panel manufacturing processes that include shearing, drying and lamination can change the physical and chemical properties of the veneer surface. These are factors to take into account in order to ensure good moistening and penetration of the adhesive (Frihart and Hunt 2010).

Various types of adhesives are employed in the manufacture of plywood panels (Stoeckel et al. 2013), among which the urea-formaldehyde (UF) resin is commonplace in conformation of veneer panels as well as particleboards, providing good resistance only in dry conditions service (Frihart and Hunt 2010, Kaboorani et al. 2013). Moreover, adhesives allow for improved use of timber by enabling the design of low density wooden products, as well as the generation of wooden pieces of greater proportions from others dimensionally lesser and the more effective exploitation of residues from other lumber industries (Zhao et al. 2011).

${ }^{1}$ Escuela de Ingeniería Forestal, Instituto Tecnológico de Costa Rica, Cartago, Costa Rica.

•Corresponding author: fmunoz@tec.ac.cr

Received: 19.12.2016 Accepted: 17.11.2017 
Developments in nanotechnology, specifically the use of nanoparticles, have led to improvements of the properties of adhesives and the resistance at the glue line between the lumber and adhesive (Cai et al. 2007, Lei et al. 2008, Ashori and Nourbakhsh 2009, Kaboorani et al. 2011, Ates et al. 2013, Xian et al. 2013, Bardak et al. 2017). However, behaviour of nano-modified adhesives in tropical species is, as of yet, not well known (Moya et al. 2015a, Moya et al. 2015b). According the Bayatkashkoli and Faegh (2014), panels made with fast growth species treated with nanotechnology are regarded as an alternative to the increment in the demand of such engineering products.

In Costa Rica, meanwhile, lumber from reforested species has gained importance in the manufacture of engineering products (Serrano and Moya 2011). Three remarkable species in reforestation are Gmelina arborea, Cordia alliodora and Vochysia ferruginea. However, more research ought to be done to generate scientific and technological knowledge in order to add value to these forest species and thus successfully transform lumber from forest plantations into engineering products. As a response, so as to make complete utilisation of these reforestation species, scientific research alternatives both basic and applied have emerged globally, which have promoted the surge of high-grade development technological products such as plywood panels. This allows for competitive incursion in new markets through the use of fast growth plantations species, due to the high resistance, efficiency and structural liability that can be obtained from them (Leichti et al. 1990a, Leichti et al. 1990b).

In these products it is possible to further improve structural performance with the use of nanoparticles, as properties of all system components (veneer-adhesive-veneer) combine at the interfacial zone to provide the final properties of the composite material (Gardner 2006, Jacob et al. 2008, Frihart and Hunt 2010) and that ultimate performance of such composite materials depends strongly on the quality of the interface (Schultz et al. 1987). It is therefore of relevance to know the behaviour of this area in order to improve the mechanical performance of products using fast growth lumber species and nanomodified resins.

On this basis, the present study has the object of determining the micro- and macro-scale effects of the modification of urea-formaldehyde (UF) adhesive using nanoclay particles at four different concentrations, as well as the unmodified adhesive $(0,00 ; 0,75 ; 1,00 ; 1,50$ and $2,00 \%)$. Evaluation of the physical-mechanical properties is done on plywood panels fabricated with three forest species from fast-growth plantations: Cordia alliodora, Gmelina arborea and Vochysia ferruginea.

\section{MATERIALS AND METHODS}

\section{Raw materials}

A total of 60 logs were used, $1 \mathrm{~m}$ long with variable diameter, of three species from forest plantations in Costa Rica with ages varying from 7 to 9 years: Cordia alliodora from Búfalo-Limón (latitude: $10^{\circ} 00^{\prime} 21^{\prime \prime} \mathrm{N}$ and longitude: $83^{\circ} 10^{\prime} 23^{\prime \prime} \mathrm{W}$ at an elevation of $25 \mathrm{~m}$ amsl and 9 years of age) and CATIETurrialba (latitude: $09^{\circ} 53^{\prime} 00^{\prime \prime} \mathrm{N}$ and longitude: $83^{\circ} 38^{\prime} 01^{\prime \prime} \mathrm{W}$ at an elevation of $602 \mathrm{~m}$ amsl and 9 years of age); Gmelina arborea from Bonifacio-Limón (latitude: 0946'43" N and longitude: 82 54 '59" W at an elevation of $42 \mathrm{~m}$ amsl and 8 years of age); and Vochysia ferruginea from Búfalo-Limón (latitude: $10^{\circ} 00^{\prime} 21^{\prime \prime} \mathrm{N}$ and longitude: $83^{\circ} 10^{\prime} 23^{\prime} \mathrm{W}$ at an elevation of $25 \mathrm{~m}$ amsl and 7 years of age). Per species, 7 to 8 trees were felled. All logs were sawn with a rotary peeling lathe in order to obtain the veneers with dimensions of 2 and $3 \mathrm{~mm}$ of thickness.

\section{Characteristics of nano-modified adhesive}

Commercial nanoclay of the brand Dellite $43 \mathrm{~B}^{\circledR}$-DMBHT was employed, manufactured by Laviosa-Chimica Mineraria, SpA, Livorno-Italia. The physical and chemical characteristics of the nanoclay are as follows: $3 \%$ moisture content, $<1 \%$ impurity content $1,6 \mathrm{~g} \mathrm{~cm}^{-3}$ density, $7-9 \mu \mathrm{m}$ particle size, organically modified with dimethyl-benzyl hydrogenated tallow ammonium. The detail on the type of nanoclay and other characteristics can be consulted in Moya et al. (2015a). The type of adhesive used was a water-based urea-formaldehyde (UF), CR-560 UF Resin trademark, produced by 
Central Chemistry Quibor SA (https://www.agroquibor.com). The technical description of the product indicates that the liquid resin is urea-formaldehyde (UF), with 64 to $65 \%$ solids content and $650-900$ cPs viscosity.

Modification of the UF adhesive with nanoclay was carried out by adding this compound at different percentages in relation to the adhesive solution (weight/weight): 0,$00 ; 0,75 ; 1,00 ; 1,50$ and $2,00 \%$ (Kaboorani and Rield 2011, Moya et al. 2015a); according to the nanoclay percentage in them, treatments were then labelled as UF-0,00 (control), UF- 0,75 ; UF-1,00; UF-1,50 and UF-2,00 respectively. The formulation of the adhesive was done according to the technical datasheet of the manufacturer, by mixing on a weight/weight ratio: UF resin at $51 \%$, wood flour as filler ingredient at $21 \%$, water at $26 \%$ and the catalyst at $3 \%$, plus the percentage of nanoclay corresponding to each treatment. In order to blend the compounds, the mixture was stirred at ambient temperature for 15 minutes at $1600 \mathrm{rpm}$ with a four-blade metal blender (blade inclination of $45^{\circ}$ ); the corresponding amount of the catalyst was then added, continuing with the constant stirring for another 10 minutes. Other details on the preparation of the adhesive formula can be found in Moya et al. (2015a). The adhesive were spread manually with a brush on the main face of the veneers, such that the adhesive coverage was approximately $250 \mathrm{~g} \mathrm{~m}^{-2}$, methodology similar to that applied by Gao and $\mathrm{Li} \mathrm{(2012)} \mathrm{and}$ Cihad and Bektaș (2014).

\section{Pressing cycle for panels and sampling}

Plywood panel fabrication was done with a hydraulic press of national craft with a total pressing capacity of $8000 \mathrm{~kg}$. The press conditions for densification of the veneers were: specific pressure of $12 \mathrm{~kg} \mathrm{~cm}^{-2}$, temperature of the plates at $160^{\circ} \mathrm{C}$ to $170{ }^{\circ} \mathrm{C}$ and pressing speed of $1 \mathrm{~min} / \mathrm{mm}$ (Lisperguer and Rozas 2005).

A total of 150 plywood panels were built ( 3 species $x 5$ concentrations $x 10$ panels), conformed in five layers with dimensions of $600 \times 600 \times 12 \mathrm{~mm}$ (Figure 1). The veneer thicknesses were set in two categories: $2 \mathrm{~mm}$ for outer veneers and $3 \mathrm{~mm}$ for inner veneers, with moisture content of the veneers at 10 to $12 \%$. The panels were then squared to $560 \times 560 \times 12 \mathrm{~mm}$ and sampled in order to determine the physical and mechanical properties, as shown in Figure 1. From each panel fabricated, at least one sample per test was obtained, therefore a total of 10 units were available for each test.

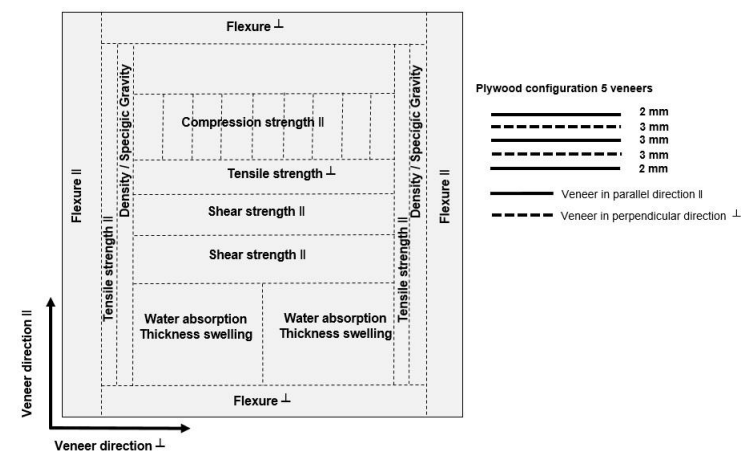

Figure 1. Distribution of samples for physical and mechanical tests on $560 \times 560 \times 12 \mathrm{~mm}$ plywood panels. Five-layer configuration for cross-laminated panels.

\section{Physical properties}

A total of 1125 samples were tested in order to determine the physical properties in accordance to the standards as follows: specific gravity at $12 \%\left(S G_{12}\right)$ complying with method B of D-2395 standard (ASTM 2003a); moisture content according to D-4442 standard (ASTM 2003b); density at $12 \%$ $\left(D E N_{12}\right)$, water absorption $(A B S)$ and thickness swelling $(T S)$ following method $\mathrm{B}$ of D-1037 standard (ASTM 2003c). 


\section{Mechanical properties}

To determine the mechanical properties, 1125 samples were tested in compliance to norms as follows: tension parallel to surface (T\|) with sample A, following method A of D-3500 standard (ASTM 2003d); compression parallel to surface (C\|) using method A.11 of D-3501 standard (ASTM 2000a); shear at the plane of the panel (S\|) using D-1037 standard (ASTM 2003c); flexure parallel and perpendicular to surface ( $F \|$ and $F^{\perp}$ respectively) as stated in method A of D-3043 standard (ASTM 2000a). All mechanical tests were carried out in a universal testing machine brand Tinius Olsen H10KT, with the exception of tension parallel to surface $(T \|)$, which was tested in a Tinius Olsen Super L machine.

\section{Electronic Microscopy}

Six samples were selected of each species: 3 samples with the control treatment and other 3 samples from panels treated with UF-0,75 adhesive containing nanoclay particles brand Dellite $43 \mathrm{~B}^{\circledR}$-DMBHT. For each sample a cross-section measuring $5 \times 5 \mathrm{~mm}$ was prepared, cutting off two of its corners to the shape of a truncated pyramid with a steel knife. The upper surface of the frustum was then cut using the glass edge of a Leica EM ultramicrotome, rendering a smooth surface with little roughness in order to increase quality of the microphotography. Scanning Electronic Microscopy (SEM) was carried out with working distance $(W D)=3,8$ to $5,8 \mathrm{~mm} ; 7,5 \mathrm{kv}$ voltage and $400 \mathrm{x}$ magnification with an instrument brand Table Microscope TM 3000, with no gold or carbon film covering the sample.

\section{Statistical analysis}

The statistical system used was SAS ${ }^{\circledR}$ PROC UNIVARIATE. A variance analysis (ANOVA) was applied to the general statistical description (average and variation coefficient) in order to establish differences among the nano-modified adhesive treatments in panels from C. alliodora, G. arborea and $V$. ferruginea. Significant differences among measurements of each treatment were evaluated with the Tukey test $(\mathrm{P}<0,01)$.

\section{RESULTS}

\section{Physical properties}

\section{Density and Specific gravity}

Addressing the physical properties evaluated, $D E N_{12}$ and $S G_{12}$ (Table 1), it was reported for the particular case of $C$. alliodora plywood-type panels that the effect of nanoclay is not statistically significant. For G. arborea panels, the $D E N_{12}$ and $S G_{12}$ values increased statistically with the addition of nanoclay to the adhesive. For panels using $V$. ferruginea, the effect of adding nanoclay was rather varied; for example, in UF-1,50 and UF-2,00 formulations, $D E N_{12}$ values increased significantly in relation to the control, whereas in the UF- 0,75 treatment the $D E N_{12}$ value decreased and, finally, no effect was observed in the UF-1,00 treatment. Moreover, the effect of nanoclay in $V$. ferruginea panels showed a very similar behavioural pattern to the one described for the $D E N_{12}$, that is, UF-1,50 and UF2,00 formulations had significantly increased $S G_{12}$ values in relation to the control, while the UF- 0,75 treatment had decreased $S G_{12}$ values and, last, the UF-1,00 showed no positive effect. 
Table 1. Density and specific gravity at $12 \%$ in cross-laminated panels using three different plantations species, glued with UF adhesive modified with Dellite $43 \mathrm{~B}^{\circledR}$-DMBHT nanoclay particles at four different concentrations.

\begin{tabular}{|c|c|c|c|c|}
\hline \multirow{2}{*}{ Physical properties } & \multirow{2}{*}{$\begin{array}{l}\text { Adhesive type } \\
\text { UF }+\% \text { nanoclay }\end{array}$} & \multicolumn{3}{|c|}{ Species } \\
\hline & & C. alliodora & G. arborea & V. ferruginea \\
\hline \multirow{5}{*}{$\operatorname{Density}_{12}\left(\mathrm{~kg} \mathrm{~m}^{3} \mathrm{~s}^{3}\right)$} & UF-0,00 & $525(5,56)^{\mathrm{a}}$ & $399(10,81)^{\mathbf{a}}$ & $414(5,00)^{\mathrm{a}}$ \\
\hline & UF-0,75 & $518(7,54)^{\mathrm{a}}$ & $446(10,01)^{b}$ & $396(7,18)^{\mathbf{b}}$ \\
\hline & UF-1,00 & $502(6,94)^{\mathrm{a}}$ & $447(6,71)^{\mathbf{b}}$ & $413(5,56)^{\mathrm{a}}$ \\
\hline & UF-1,50 & $529(4,25)^{\mathrm{a}}$ & $462(4,84)^{b}$ & $435(4,11)^{\mathbf{c}}$ \\
\hline & UF-2,00 & $526(5,88)^{\mathrm{a}}$ & $462(4,75)^{\mathbf{b}}$ & $444(3,63)^{\mathrm{c}}$ \\
\hline \multirow{5}{*}{ Specific Gravity $_{12}$} & UF-0,00 & $0,48(5,92)^{\mathbf{a}}$ & $0,35(10,35)^{\mathbf{a}}$ & $0,38(4,93)^{\mathrm{a}}$ \\
\hline & UF-0,75 & $0,45(7,29)^{\mathrm{a}}$ & $0,39(8,23)^{\mathbf{b}}$ & $0,35(7,46)^{\mathbf{b}}$ \\
\hline & UF-1,00 & $0,46(7,22)^{\mathbf{a}}$ & $0,41(6,52)^{b}$ & $0,38(5,22)^{\mathrm{a}}$ \\
\hline & UF-1,50 & $0,48(4,67)^{\mathrm{a}}$ & $0,42(7,78)^{b}$ & $0,40(4,14)^{\mathrm{c}}$ \\
\hline & UF-2,00 & $0,48(5,80)^{\mathrm{a}}$ & $0,42(4,61)^{\mathbf{b}}$ & $0,41(3,55)^{\mathrm{c}}$ \\
\hline
\end{tabular}

Average value of the physical property for each species; per cent coefficient of variation between parentheses. Different letters indicate significant statistical differences with $\alpha=0,05$.

\section{Change in moisture content}

Figure 2A, Figure 2B and Figure 2C show the percentage of change in moisture content $(\triangle M C)$ of panels after 24-hour immersion in water. The addition of nanoclay to the adhesive formulation significantly reduced the $\triangle M C$ in all treatments for plywood panels of all species but the UF-1,00 treatment in C. alliodora panels (Figure 2A). Particularly for panels using C. alliodora and G. arborea, the UF- 0,75 treatment showed the best significantly positive effect for reduction of $\triangle M C$ percentage in relation to the control treatment. However, UF-1,00; UF-1,50 and UF-2,00 treatments were more effective in reducing $\triangle M C$ percentage in $V$. ferruginea panels (Figure $2 \mathrm{C}$ ). In $C$. alliodora panels, a significant statistical difference was determined in relation to the control for UF- 0,75 ; UF-1,50 and UF2,00 treatments, with no significant difference between UF-1,50 and UF-2,00 treatments (Figure 2B). Meanwhile in G. arborea panels, a significant statistical difference was determined for all treatments in relation to the plywood control, but no significant statistical difference appeared between UF-1,50 and UF-2,00 treatments (Figure 2B). Similarly, in V. ferruginea panels a significant statistical difference was determined for all treatments in relation to the control, while none was shown between UF-1,00; UF-1,50 and UF-2,00 treatments.

\section{Water absorption}

Figure 2D, Figure 2E and Figure 2F show the percentage of water absorption $(A B S)$ of plywood panels after 24-hour immersion in water. The effect of nanoclay addition to the adhesive formulation for $A B S$ reduction was more evident in $V$. ferruginea panels, particularly in UF-1,00; UF-1,50 and UF2,00 treatments in this case, wherein $A B S$ was shown to decrease significantly in relation to the control (Figure 2F) and also in comparison to panels of the other two species. For $C$. alliodora panels, the most significant reduction in $A B S$ in relation to the control was achieved with the UF-0,75 treatment (Figure 2D), while for $G$. arborea panels the $A B S$ was decreased with UF-0,75 and UF-1,00 treatments (Figure 2E). For C. alliodora, a significant statistical difference from the control was only determined in UF0,75 and UF-1,00 treatments, as well as a difference between these two. For $G$. arborea, significant statistical difference was determined in all treatments, with no difference between UF- 0,75 and UF1,00 nor between UF-1,50 and UF-2,00.

\section{Thickness swelling}

The percentage of thickness swelling (TS) of plywood panels after 24-hour immersion in water is shown in Figure 2G, Figure $2 \mathrm{H}$ and Figure 2I. The addition of $2 \%$ nanoclay concentration to the 
adhesive formulation had the greatest significantly positive impact on the TS decrease for panels of all species. The highest statistical TS value was found in evaluation of C. alliodora panels glued with UF-1,00 while the lowest $T S$ percentages in relation to the control were obtained with UF- 0,75 and UF-2,00 treatments (Figure 2G), with a significant statistical difference between the two treatments. In $G$. arborea panels, meanwhile, all treatments reduced the $T S$ percentage significantly in relation to the control; though no significant difference was detected between the UF-nanoclay treatments (Figure $2 \mathrm{H})$. Finally, in $V$. ferruginea panels the addition of nanoclay at concentrations of 0,75 and $1,00 \%$ did not show statistical differences in relation to control panels; the UF-1,50 and UF-2,00 treatments though, with a significant statistical difference between them, reported a statistically lower decrease in the TS percentage in comparison to the other concentrations (Figure 2E).

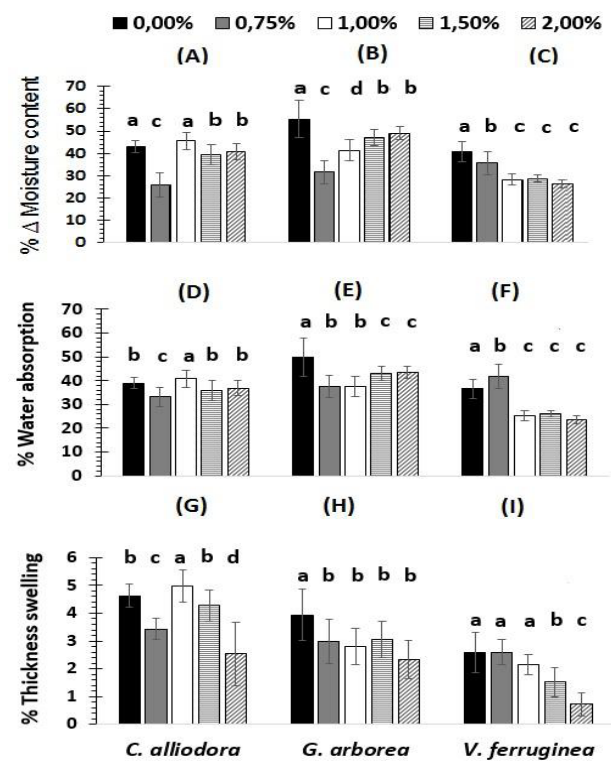

Figure 2. Physical properties: percentage of change in moisture content, percentage of water absorption and percentage of thickness swelling for plywood from 3 species glued with UF adhesive nano-modified by Dellite $43 \mathrm{~B}^{\circledR}$-DMBHT nanoclay.

Note: different letters on bars indicate significant statistical differences at $\alpha=0,05$.

\section{Mechanical properties}

\section{Flexure test}

Mechanical strength in parallel flexure, determined through the modulus of rupture $(M O R \|)$ and modulus of elasticity $(M O E \|)$, showed that plywood panels of the three species using UF- 0,75 adhesive formulation obtained the highest statistical values for mechanical strength in relation to the control treatment and the other formulations (Figure 3A, Figure 3B, Figure 3C, Figure 3D, Figure 3E, Figure $3 \mathrm{~F})$. Specifically, C. alliodora panels using UF-1,00 reported the statistically lowest $M O R \|$ and $M O E \|$ values. Results obtained for $G$. arborea panels using either UF-1,00; UF-1,50 or UF-2,00 treatments, similarly, did not show such significantly positive effect for the $M O R \|$ and $M O E \|$ values in relation to the control treatment (Figure 3B and Figure 3E). In the case of $V$. ferruginea panels, UF-1,00 and UF1,50 treatments presented an $M O R \|$ value statistically lower in relation to the control, but it was the only species to report an increase in the $M O R \|$ value with the UF-2,00 treatment (Figure 3C).

The evaluation of mechanical strength in perpendicular flexure for $C$. alliodora panels showed statistically higher values for the modulus of rupture $(M O R \perp)$ and modulus of elasticity $\left(M O E^{\perp}\right)$ in those panels treated with UF-0,75 as compared to other treatments (Figure 3G, Figure 3J), while the lowest statistical $M O R^{\perp}$ value was obtained in UF-1,00 panels and no statistical differences were shown in the $M O E^{\perp}$ among panels with 1,$00 ; 1,50$ and 2,00\% nanoclay concentrations in relation to the control 
(Figure 3G, Figure 3J). In G. arborea panels, all nanoclay concentrations caused a significantly positive increase in $M O R \perp$ and $M O E^{\perp}$ values in relation to the control, although no statistical difference was determined among the treatments (Figure $3 \mathrm{H}$, Figure $3 \mathrm{~K}$ ). For panels from $V$. ferruginea, only the UF0,75 treatment presented a significant increase, whereas the other treatments had no effect since the $M O R^{\perp}$ value obtained with them was statistically equal to that of the control treatment (Figure 3I). In addition, UF-1,00; UF-1,50 and UF-2,00 treatments caused a significant decrease in the $M O E^{\perp}$ of $V$. ferruginea panels, while in UF-0,75 the value was statistically equal to that of the control treatment (Figure 3I, Figure 3L); however, the highest value for $M O E^{\perp}$ was reported in the UF-0,75 treatment for this species (Figure 3L).
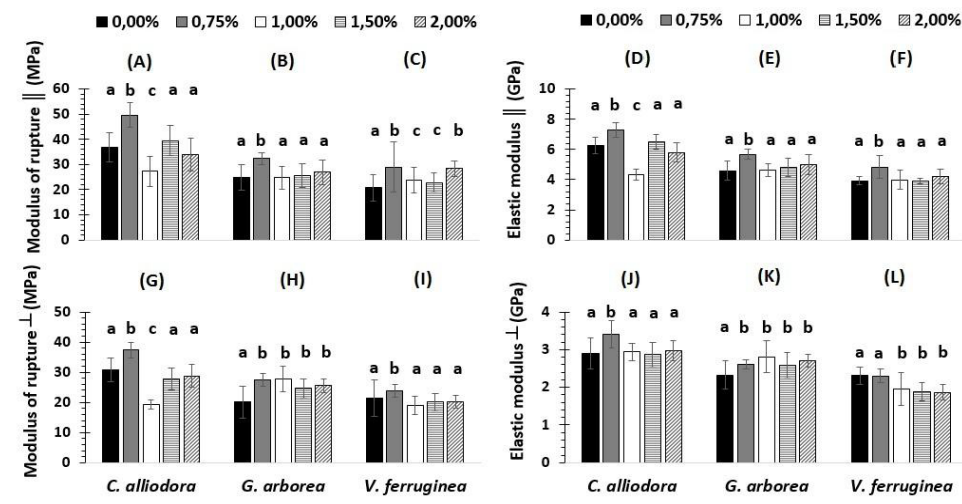

Figure 3. Mechanical properties: modulus of rupture and modulus of elasticity for flexure in parallel and perpendicular orientations for plywood from three species glued with UF adhesive nano-modified by Dellite $43 \mathrm{~B}^{\circledR}$-DMBHT nanoclay.

Note: different letters on bars indicate significant statistical differences at $\alpha=0,05$.

\section{Test for strength in compression, shear and tension}

It was found in the test for strength in parallel compression that plywood panels using UF- 0,75 treatment showed the highest statistical value in all three species studied, in comparison to control samples and the other treatments. The lowest values for strength in compression, on the other hand, were observed as follows: for UF-1,00 in C. alliodora panels; for UF-1,50 in G. arborea panels; and for UF-1,00 and UF-1,50 treatments in $V$. ferruginea (Table 2). In testing for strength in parallel shear it was found that panels of all species fabricated using the adhesive with no nanoclay (UF-0,00) showed a lower strength value when compared to nanoclay-modified UF treatments. Plywood panels glued with UF-1,50 in C. alliodora and G. arborea and those using UF-2,00 in V. ferruginea reported the lowest shear strength values among panels treated with nanoclay-modified UF (Table 2).

Evaluation of strength in parallel tension revealed that panels of all species manufactured with nanoclay-free adhesive also presented the least strength for this mechanical test (Table 2). Meanwhile, the maximum values for strength in tension were found in C. alliodora and V. ferruginea panels using the UF-0,75 treatment, as well as $G$. arborea panels with the UF-2,00 treatment. Last, comparing the treatments using nanoclay-modified UF, the lowest value obtained for strength in tension came from control-treated C. alliodora panels and from UF-1,50 panels in G. arborea and V. ferruginea (Table 2). 
Table 2. Mechanical properties: compression strength, shear strength and tensile strength in parallel orientation for plywood from three species glued with UF adhesive nano-modified by Dellite $43 \mathrm{~B}^{\mathbb{R}}$.

\section{DMBHT nanoclay.}

\begin{tabular}{|c|c|c|c|c|}
\hline \multirow{2}{*}{ Mechanical properties } & \multirow[t]{2}{*}{$\begin{array}{l}\text { Adhesive type } \\
\text { UF+ } \% \text { nanoclay }\end{array}$} & \multicolumn{3}{|c|}{ Species and strength $(\mathrm{MPa})$} \\
\hline & & C. alliodora & G. arborea & V. ferruginea \\
\hline \multirow{5}{*}{ Strength in Parallel Compression } & UF- 0,00 & $18,59(8,44)^{b}$ & $12,74(8,80)^{\mathrm{c}}$ & $12,15(7,04)^{\mathrm{c}}$ \\
\hline & UF- 0,75 & $22,80(5,06)^{a}$ & $16,64(3,59)^{\mathrm{a}}$ & $14,35(4,09)^{\mathrm{a}}$ \\
\hline & UF- 1,00 & $17,00(6,99)^{\mathrm{c}}$ & $15,30(15,34)^{a}$ & $12,62(4,34)^{\mathrm{c}}$ \\
\hline & UF- 1,50 & $19,13(6,88)^{b}$ & $14,66(6,01)^{b}$ & $12,98(7,39)^{\mathrm{c}}$ \\
\hline & $\mathrm{UF}-2,00$ & $18,46(10,71)^{b}$ & $16,55(8,48)^{\mathrm{a}}$ & $13,37\left(4,31^{) b}\right.$ \\
\hline \multirow{5}{*}{ Strength in Parallel Shear } & UF- 0,00 & $1,93(20,76)^{b}$ & $1,38(20,47)^{b}$ & $1,32(36,58)^{\mathrm{a}}$ \\
\hline & UF- 0,75 & $2,54(6,78)^{\mathrm{a}}$ & $2,12(23,67)^{c}$ & $1,94(9,40)^{b}$ \\
\hline & UF- 1,00 & $2,45(8,93)^{\mathrm{a}}$ & $2,75(11,17)^{\mathrm{a}}$ & $2,10(15,96)^{b}$ \\
\hline & $\mathrm{UF}-1,50$ & $2,09(23,40)^{\mathrm{b}}$ & $2,32(12,69)^{\mathrm{a}}$ & $1,90(17,28)^{b}$ \\
\hline & $\mathrm{UF}-2,00$ & $2,87(10,32)^{a}$ & $2,55(11,52)^{\mathrm{a}}$ & $1,86(11,90)^{\mathrm{b}}$ \\
\hline \multirow{5}{*}{ Strength in Parallel Tension } & UF- 0,00 & $27,10(17,23)^{b}$ & $18,41(21,51)^{\mathrm{a}}$ & $15,08(21,59)^{\mathrm{c}}$ \\
\hline & $\mathrm{UF}-0,75$ & $37,63(11,33)^{\mathrm{a}}$ & $24,48(15,70)^{b}$ & $20,98(12,74)^{\mathrm{a}}$ \\
\hline & $\mathrm{UF}-1,00$ & $32,26(21,66)^{\mathrm{c}}$ & $24,16(17,70)^{b}$ & $16,62(13,19)^{\circ}$ \\
\hline & $\mathrm{UF}-1,50$ & $32,24(11,32)^{\mathrm{c}}$ & $23,11(23,46)^{b}$ & $16,31(6,92)^{\mathrm{c}}$ \\
\hline & UF- 2,00 & $30,82(21,54)^{b}$ & $26,54(13,95)^{b}$ & $19,06(14,30)^{\mathrm{a}}$ \\
\hline
\end{tabular}

Average value of the mechanical property for each species; coefficient of variation percentage between parentheses.

Different letters indicate significant statistical differences with $\alpha=0,05$.

\section{Glue line}

No evidence of change was observed in the colour of the glue line at plain sight in the various plywood panels glued with UF and nanoclay at different concentrations, as is shown in Figure 4. The thickness of the glue line in panels using the UF- 0,00 treatment, determined by means of micrometric measurements taken with electronic microscopy along a length of $200 \mu \mathrm{m}$ in the interfacial zone (Figure 5), revealed the following values: $90 \mu \mathrm{m}$ for C. alliodora, $46 \mu \mathrm{m}$ for $G$. arborea and $15 \mu \mathrm{m}$ for V. ferruginea (Figure 5A, Figure 5B, Figure 5C).

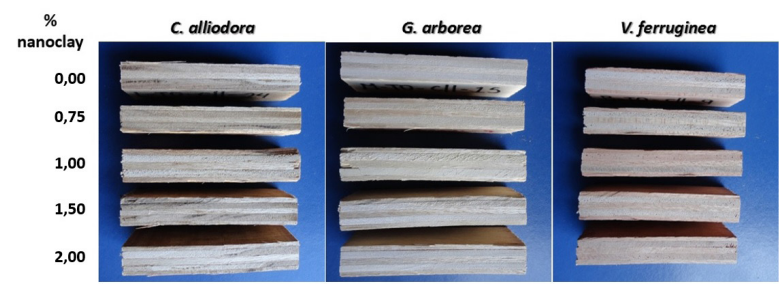

Figure 4. General view of the glue lines in plywood panels built with C. alliodora, G. arborea and $V$. ferruginea veneers, glued with urea-formaldehyde adhesive modified with nanoclay at different concentrations.
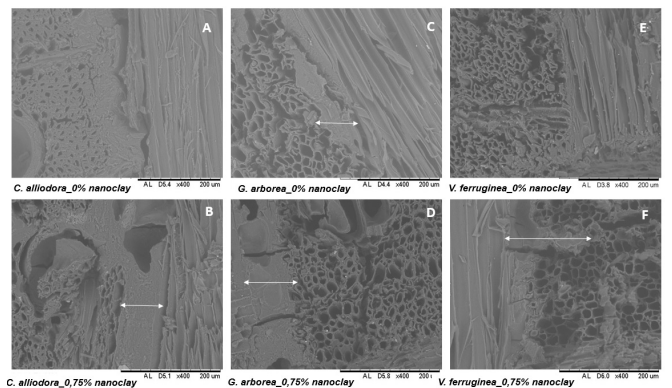

Figure 5. Microphotographs of the glue line and interfacial zone of cross-laminated panel samples, obtained at 400x electronic microscopy: (A) C. alliodora with UF-0,00 formulation; (B) C. alliodora

with UF-0,75 formulation; (C) G. arborea with UF-0,00 formulation; (D) G. arborea with UF0,75 formulation; (E) $V$. ferruginea with UF-0,00 formulation; and (F) $V$. ferruginea with UF-0,75 formulation. 


\section{DISCUSSION}

\section{Physical properties}

According to Shukla and Pascal (2008), physical properties in plywood panels, such as density and specific weight, are affected by the type and conditions of each species and, in very scarce cases, by the manufacturing process of the panels. This statement agrees well with results reported in Table 1 , where species with greater base specific gravity yielded higher $S G_{12}$ and $D E N_{12}$ values: panels built with $C$. alliodora veneers ( $S G=0,46$; Tenorio et al. 2016) obtained the highest $S G_{12}$ and $D E N_{12}$ values; intermediate values were obtained with $G$. arborea lumber panels $(S G=0,41$; Tenorio et al. 2016); and the lowest values appeared in panels made with $V$. ferruginea lumber $(S G=0,35$; Tenorio et al. 2016). Additionally, the use of nanoclay in the adhesive increased the $D E N_{12}$ and $S G_{12}$ values in relation to panels using UF-0,00 especially in C. alliodora and G. arborea panels (Table 1). This increase in the value of these properties is a product of the increment in mass from the added nanoclay in the adhesive. Each panel is composed of four glue lines with a greater weight percentage, attributed to nanoclay (from 0,75 to $2,00 \%$ ).

In the case of $\triangle M C, A B S$ and $T S$ of plywood panels (Figure 2), a generalised behaviour was observed, which was the decrease in the average values of these properties in relation to the control treatment. This means that the application of nanoclay-modified UF resin improved the behaviour of panels in presence of water.

The behaviour described above is congruent with results reported by Cai et al. (2007), Doosthoseini and Zarea-Hosseinabadi (2010), Abdul et al. (2010) and Lei et al. (2010) for various temperate-climate species. These authors indicate that the increment of nanoclay in a polymer matrix produces a decrease of the swelling and water absorption values, resulting in augmented resistance to moisture of the plywood panel.

The general effect of modifying UF adhesive with nanoclay is the positive decrease of $\triangle M C, A B S$ and TS. In regards to this, Mansouri et al. (2006) indicate that urea-formaldehyde resins are the most widely employed adhesives in plywood panels for indoor use. However, a disadvantage of UF-type resins is presented at the glue line, as these resins have a high sensitivity to moisture. Therefore, treatment with the UF-type adhesive modified by Dellite $43 \mathrm{~B}^{\circledR}$-DMBHT nanoclay allows for improvements on the performance under moisture conditions of plywood panels of the species studied.

Lei et al. (2008) presented a hypothesis that all montmorillonite nanoclay itself is water-repellent. Later, Kaboorani and Riedl (2011) mentioned that nanoclay could modify the response of a polymer to a load by means of several mechanisms. Nanoclay particles have an inherently high surface area to volume ratio, leading to large interfacial area between the fillers and matrix. This condition, then, could be manifested in a decrease in moisture absorption in the glue line.

\section{Mechanical properties}

Values of the various mechanical properties reflect the characteristics of each species studied. Plywood panels made of $C$. alliodora, with a $S G$ of 0,46 (Tenorio et al. 2016), showed the highest values for the mechanical properties and, consequently, V. ferruginea panels with a $S G$ of 0,35 (Tenorio et al. 2016) presented the lowest strength values (Table 2, Figure 3). Concerning this, Shukla and Pascal (2008) indicate that the density of the timber is considered an indicator of the mechanical or strength properties of products to be fabricated from it.

The modulus of elasticity is the resistance to deflection (deformation) exerted by the plywood panel and it is considered one of the most important mechanical properties of materials, as it affects their service performance in loaded applications (Bayatkashkoli and Faegh 2014). In this way, products or conditions with greater $M O E$ or $M O R$ values in flexure are indicative of materials with better mechanical performance. Therefore, panels glued with UF-0,75 show the best performance in flexural strength for both parallel $(\|)$ and perpendicular $\left({ }^{\perp}\right)$ orientations, as they present the highest statistical values in all species (Figure 3 ). 
Results obtained from the other mechanical tests, such as maximum parallel compression and tensile strengths, suggest that the use of UF resin with $0,75 \%$ nanoclay treatment is most adequate for improvement of the mechanical properties of cross-laminated panels. However, in the case of parallel shear strength, the effect of the treatment varies more in relation to the nanoclay amount added to the resin. For example, in C. alliodora panels, the maximum parallel shear strength was achieved when the UF adhesive was applied at 2,00\% nanoclay, whereas in G. arborea and $V$. ferruginea the highestscoring nanoclay content was $1,00 \%$ (Table 2). It is to be noted, though, that the magnitude of the shear mechanical strength value in all panels with nanoclay treatment surpassed that of mechanical strength in control plywood panels.

The addition of nanoclay to various types of adhesive has been shown to improve mechanical properties at the glue line (Lei et al. 2008, Kaboorani and Riedl 2011, Kaboorani et al. 2012, Kaboorani et al. 2013, Pique et al. 2013, Pirayesh et al. 2013, Xian et al. 2013, Ates et al. 2013). A similar result was obtained in Moya et al. (2015b), wherein shear strength at the glue line of Carapa guianensis hardwood was improved by using nanoclay-modified UF resin.

The improvement of the shear strength can be explained by the work of Kaboorani and Riedl (2011). They mentioned that mechanical properties of PVAc and UF are affected by adding nanoclay. Nanoclay can modify the response of a polymer to a load by means of several mechanisms. Nanoclay particles have an inherently high surface area to volume ratio, leading to large interfacial area between the fillers and matrix. This suggests that there is an interaction zone surrounding each filler particle which substantially alters the physical properties relative to the neat polymer matrix, such as higher or lower polymer mobility, entanglement density and altered modulus. Also, the polymer-clay nanocomposites exhibit extremely strong interface with polymers due to the confinement of polymer chains within the galleries of clay platelets. It is considered that the confinement of polymer-clay interactions would affect the local chain dynamics to a certain extent.

The effects of the UF resin modification with nanoclay at different concentrations compared to those of using regular UF adhesive, for plywood panels of all three species studied, are shown in Table 3. Nanomodification of the UF was less effective in C. alliodora panels, whereas very effective in G. arborea and $V$. ferruginea panels. In general and as has been indicated, an improvement of behaviour takes place there in presence of water, as well as an important intensification of the properties in the timber. Furthermore, it is observed that the addition of nanoclay at a concentration of $0,75 \%$ accentuates the mechanical properties in panels of the three species (Table 3).

Table 3. Increment and decrement of physical and mechanical properties in plywood panels of three plantation species glued with UF-type adhesive modified with Dellite $43 \mathrm{~B}^{\circledR}$-DMBHT nanoclay at four different concentrations.

\begin{tabular}{|c|c|c|c|c|c|c|c|c|c|c|c|c|}
\hline \multirow[t]{3}{*}{ Property } & \multicolumn{4}{|c|}{ C. alliodora } & \multicolumn{4}{|c|}{ G. arborea } & \multicolumn{4}{|c|}{ V. ferruginea } \\
\hline & UF & UF & UF & UF & UF- & UF & UF & UF & UF & UF & UF & UF \\
\hline & $0,75 \%$ & $1,00 \%$ & $1,50 \%$ & $2,00 \%$ & $0,75 \%$ & $1,00 \%$ & $1,50 \%$ & $2,00 \%$ & $0,75 \%$ & $1,00 \%$ & $1,50 \%$ & $2,0 \%$ \\
\hline$D E N_{12}$ & $(-)$ & $(--)$ & $(-)$ & $(-)$ & $\pi(12)$ & $\pi(12)$ & $\pi(16)$ & $\pi(16)$ & $\Downarrow(5)$ & $(-)$ & $\pi(5)$ & $\pi(7)$ \\
\hline$S G_{12}$ & $(\leftrightarrow)$ & $(-)$ & $(-)$ & $(-)$ & $\pi(12)$ & $\Uparrow(17)$ & $\pi(20)$ & $\pi(20)$ & $\Downarrow(8)$ & $(-)$ & $\pi(5)$ & $\pi(8)$ \\
\hline$\Delta M C$ & $\Downarrow(40)$ & $(-)$ & $\Downarrow(9)$ & $\Downarrow(5)$ & $\Downarrow(43)$ & $\Downarrow(25)$ & $\Downarrow(15)$ & $\Downarrow(11)$ & $\Downarrow(13)$ & $\Downarrow(31)$ & $\Downarrow(29)$ & $\Downarrow(35)$ \\
\hline$A B S$ & $\Downarrow(15)$ & $(-)$ & $\Downarrow(8)$ & $(-)$ & $\Downarrow(24)$ & $\Downarrow(24)$ & $\Downarrow(13)$ & $\Downarrow(13)$ & $\pi(14)$ & $\Downarrow(31)$ & $\Downarrow(29)$ & $\Downarrow(35)$ \\
\hline$T S$ & $\Downarrow(26)$ & $\pi(8)$ & $(-)$ & $\Downarrow(45)$ & $\Downarrow(24)$ & $\Downarrow(28)$ & $\Downarrow(22)$ & $\Downarrow(41)$ & $(-)$ & $\Downarrow(17)$ & $\Downarrow 41)$ & $\Downarrow(72)$ \\
\hline MORI & $\pi(35)$ & $\Downarrow(26)$ & $(-)$ & $(-)$ & $\pi(30)$ & $(-)$ & $(-)$ & $(-)$ & $\pi(40)$ & $(-)$ & $(-)$ & $\pi(37)$ \\
\hline$M O E \|$ & $\pi(17)$ & $\Downarrow(31)$ & $(-)$ & $(-)$ & $\pi(24)$ & $(-)$ & $(-)$ & $(-)$ & $\pi(23)$ & $(-\cdot)$ & $(-)$ & $(-)$ \\
\hline$M O R^{\perp}$ & $\pi(21)$ & $\Downarrow(38)$ & $(-)$ & $(\because)$ & $\pi(36)$ & $\pi(38)$ & $\pi(23)$ & $\pi(27)$ & $\pi(12)$ & $(-)$ & $(\because)$ & $(-)$ \\
\hline$M O E^{\perp}$ & $\pi(17)$ & $(-)$ & $(-)$ & $(-)$ & $\pi(13)$ & $\pi(21)$ & $\pi(11)$ & $\pi(16)$ & $(-)$ & $\Downarrow(16)$ & $\Downarrow(18)$ & $\Downarrow(19)$ \\
\hline $\mathrm{Cl}$ & $\pi(23)$ & $(-)$ & $(-)$ & $(-)$ & $\pi(31)$ & $\pi(20)$ & $\pi(15)$ & $\pi(29)$ & $\pi(18)$ & $(-)$ & $(-)$ & $\pi(10)$ \\
\hline$S \mathbb{S I}$ & $\pi(32)$ & $\pi(27)$ & $(-)$ & $\pi(48)$ & $\pi(54)$ & $\pi(30)$ & $\pi(68)$ & $\pi(85)$ & $\pi(47)$ & $\pi(59)$ & $\pi(44)$ & $\pi(41)$ \\
\hline$T \pi$ & $\pi(38)$ & $\Uparrow(19)$ & $\pi(19)$ & $\pi(13)$ & $\pi(33)$ & $\pi(33)$ & $\pi(26)$ & $\pi(44)$ & $\pi(39)$ & $(-)$ & $\pi(26)$ & $\pi(26)$ \\
\hline
\end{tabular}


According to the literature, there are discrepancies associated to the amount of nanoclay that is to be added to wood adhesives in order to raise the mechanical strength of plywood products. Lei et al. (2010), for example, reported an increase of parallel tension properties of Pinus sylvestris plywood panels when nanoclay was added to PUF resin at amounts less than $3 \%$. In another study (Lei et al. 2008) the $M O E$ of plywood panels was increased by adding nanoclay of various types at different proportions to the UF adhesive, reaching the maximum $M O E$ with around $4 \%$ nanoclay, beyond which this value decreased, additionally increasing the viscosity of the adhesive mixture and complicating the homogenous diffusion of nanoparticles, thus negatively affecting the setting of the resin. On the other hand, Moya et al. (2015a) found that the optimal concentration for the shear strength at the glue line in tropical lumber species is $1 \%$, which is close to the percentage presented in this study. When increased to $1,50 \%$, however, the contrary occurs: a decrease in shear strength.

Results for the mechanical properties in this study are congruent with those of other studies, as an addition of over $1 \%$ nanoclay particles to the adhesive causes a decrease in the properties of plywood panels (Table 3). The amount of nanoclay in an adhesive mixture must be adequate since the particles tend to agglomerate at higher concentrations, bringing about the formation of lumps in the polymeric matrix of the adhesive, in this case UF, hence a decrease in strength (Kaboorani et al. 2012, Kaboorani et al. 2013, Moya et al. 2015b).

\section{Glue line}

A positive aspect of modifying the UF resin with Dellite $43 \mathrm{~B}^{\circledR}$-DMBHT nanoclay is that this does not change, at least visually, the colour of the glue line (Figure 4), therefore the aesthetic quality of products fabricated with the adhesive formulations studied would not be affected.

Scanning electronic microscopy (SEM) tests and micrometric measurement taken at the interfacial zone allowed to determine the thickness of the glue line of the various nanoclay-treated plywood panels, yielding the following values: $90 \mu \mathrm{m}$ for $C$. alliodora, $46 \mu \mathrm{m}$ for $G$. arborea and $15 \mu \mathrm{m}$ for V. ferruginea (Figure 5A, Figure 5C, Figure 5E). Nano-modification of the UF adhesive with Dellite $43 \mathrm{~B}^{\circledR}$-DMBHT nanoclay particles at $0,75 \%$ produced a significant increase of the properties in the cross-laminated panels. With this nanoclay concentration, a more uniform glue line was observed, which allowed it to transfer and distribute strains more effectively when panels underwent parallel flexure strains (Figure 5B, Figure 5D, Figure 5F). Meanwhile, in the case of Figure 5F, the generation of an interface ranging from $235 \mu \mathrm{m}$ to $262 \mu \mathrm{m}$ was determined, which indicates the adhesive became diffused at the interior of the cell structure of the wood, enabling a transition zone which favoured mechanical properties at the macro level.

It is likely that this nanoclay concentration allowed the UF resin to create the primary adhesion mechanism at the interfacial region between the adhesive and the solid wood, which is the interlocking mechanism through which the adhesive holds on to porous structures such as wood (Vick 1999). Effectivity of this interlocking mechanism is obtained when the adhesive can penetrate beyond the surface to a depth of at least 2 to 6 cells, giving place to an effective transition zone between adhesive and veneer, as happens when nanoclay concentrations of $0,75 \%$ are present in the adhesive, which can be observed in Figure 5F. This means the interface is the region where properties of all system components are combined, thus yielding the final properties of the composite material (Pukánszky 2005, Gadner 2006, Jacob et al. 2008, Frihart and Hunt 2010).

\section{CONCLUSIONS}

Modification of the adhesive formulation with nanoclay did not show a significant effect on the density and specific weight of plywood panels, but it managed to significantly decrease the statistical percentage of swelling and water absorption of panels of the three species, therefore there is an improvement in the properties of this sort of tropical lumber panels in presence of water.

For all plywood panels, in general, application of the UF adhesive with nanoclay treatment at $0,75 \%$ obtained the best mechanical performance of MOR and MOE in both parallel $(\|)$ and perpendicular $(\perp)$ 
orientations, determining a significant statistical difference relative to the control treatment. Likewise, other properties were also improved with the other treatments; nonetheless this concentration was effective for the three lumber species studied, which was not achieved with the other concentrations.

Tests at the micro-scale by means of electronic microscopy evidenced that the addition of Dellite $43 \mathrm{~B}^{\circledR}$-DMBHT nanoclay particles at $0,75 \%$ improved the glue line and interfacial regions, allowing for distribution and transference of mechanical strains to be more homogenous.

\section{ACKNOWLEDGEMENTS}

To the Vicerrectoria de Investigación y Extensión (VIE) of the Instituto Tecnológico de Costa Rica (TEC) for funding of the project. To companies Maderas Cultivadas de Costa Rica S.A., PROGASA, Aserradero Aserrín S.A., FAPACO S.A. and Centro Agronómico Tropical de Investigación y Enseñanza (CATIE) for providing the material and logistical support for the study. To the Laboratorio Institucional de Microscopía Electrónica VIE/TEC for the scanning electronic microscopy (SEM) tests.

\section{REFERENCES}

Abdul, H.; Nurul, M.; Bhat. A.; Jawaid, M.; Nik, NA. 2010. Development and material of new hybrid plywood from oil palm biomass. Materials and Design 31: 417-424.

Ashori, A.; Nourbakhsh, A. 2009. Effects of nanoclay as reinforcement filler on the physical and mechanical properties of wood-base composite. Journal of Composite Materials 43(18):1869-1875.

ASTM - American Society for Testing and Materials. 2000a Standard Test methods for woodbased structural panels in compression. D3501-94. Annual book of ASTM standards, Vol. 04.10. West Conshohocken, Philadelphia. 6 p.

ASTM - American Society for Testing and Materials. 2000b Standard test methods for structural panels in flexure. D3043-00. Annual book of ASTM standards, Vol. 04.10. West Conshohocken, Philadelphia. $13 \mathrm{p}$.

ASTM - American Society for Testing and Materials. 2003a. D2395-02: Standard test methods for specific gravity of wood and wood-base materials. Annual book of ASTM standards, Vol. 04.10. West Conshohocken, Philadelphia. 8 p.

ASTM - American Society for Testing and Materials. 2003b. Standard test methods for direct moisture content measurement of wood and wood-base materials. D4442-92. Annual book of ASTM standards, Vol. 04.10. West Conshohocken, Philadelphia. 6 p.

ASTM - American Society for Testing and Materials. 2003c. Standard test methods for evaluating properties of wood-base fiber and particle panel materials. D1037-99. Annual book of ASTM standards, Vol. 04.10. West Conshohocken, Philadelphia. 31 p.

ASTM - American Society for Testing and Materials. 2003d. Standard test methods for structural panels in tension. D3500-90. Annual book of ASTM standards, Vol. 04.10. West Conshohocken, Philadelphia. $6 \mathrm{p}$.

Ates, E.; Uyanik, N.; Kizilcan, N. 2013. Preparation of urea formaldehyde resin/layered silicate nanocomposites. Pigment \& Resin Technology 42(5): 283-287.

Bardak, T.; Naci, A.; Tankut, N.; Aydemir, D.; Sozen, E. 2017. The bending and tension strength of furniture joints bonded with polyvinyl acetate nanocomposites. Madera-Cienc Tecnol 19(1): 51-62.

Bayatkashkoli, A.; Faegh, M. 2014. Evaluation of mechanical properties of laminated strand lumber and oriented strand lumber made from Poplar wood (Populus deltoides) and Paulownia (Pau- 
lownia fortunei) with urea formaldehyde adhesive containing nanoclay. International Wood Products Journal5(4): 192-195.

Bodig, J.; Jayne, B. 1993. Mechanics of Wood and Fiber Composites. Krieger Publishing Company, Melbourne-Florida.

Cai, A.; Riedl, B.; Zhang, S.Y.; Wan, H. 2007. Effects of nanofillers on water resistance and dimensional stability of solid wood modified by melamine-urea-formaldehyde resin. Wood and Fiber Science 39(2): 307-318.

Cihad, B.; Bektaș, I. 2014. Some mechanical properties of plywood produced from Eucalyptus, Beech, and Poplar veneer. Maderas-Cienc Tecnol 16(1): 99-108.

Doosthoseini, K.; Zarea-Hosseinabadi, H. 2010. Using $\mathrm{Na}^{+} \mathrm{MMT}$ nanoclay as a secondary filler in plywood manufacturing. J Indian Acad Wood Sci 7(1-2): 58-64.

Frihart, C.; Hunt, C. 2010. Adhesives with wood materials bond formation and performance. Chapter 10. In: Wood Handbook-Wood as an engineering material. Centennial edition. Robert J. Ross Editor. General Technical Report. FPL-GTR-190. Madison, WI: U.S. Department of Agriculture, Forest Service, Forest Products Laboratory: 1-24.

Gao, W.; Li, J. 2012. Influence of uron resins on the performance of uf resins as adhesives for plywood. Maderas-Cienc Tecnol 14(1): 3-12.

Gardner, D. 2006. Adhesion mechanisms of durable wood adhesive bonds. Chapter 19. In: Characterization of the Cellulosic Cell Wall. Eds.; Douglas Stokke and Leslie Groom. Blackwell Publishing: Ames IOWA-USA: 254-265.

Jacob, M.; Anandjiwala, R.; Thomas, S. 2008. Characterization of interfaces in composites using micro-mechanical techniques. Chapter 20. Part IV Vinyl polymer technology. In: Handbook of Vinyl Polymers: Radical polymerization, Process and Technology. $2^{\text {nd }}$ edition. Mumaya Mishra and Yusuf Yagci eds. 689-716.

Kaboorani, A.; Riedl, B. 2011. Effect of adding nano-clay on performance of polyvinyl acetate (PVA) as a wood adhesive. Composites Part A: Applied Science and Manufacturing 42: 1031-1039.

Kaboorani, A.; Riedl, B.; Blanchet, P.; Fellin, M.; Hosseinaei, O.; Wang, S. 2012. Nanocrystalline cellulose (NCC): A renewable nano-material for polyvinyl acetate (PVA) adhesive. European Polymer Journal 48: 1829-1837.

Kaboorani, A.; Riedl, B.; Blanchet, P. 2013. Ultrasonication technique: a method for dispersing nano-clay in wood adhesives. Journal of Nanomaterials 3: 1-9.

Lei, H.; Du, G.; Pizzi, A.; Celzard, A. 2008. Influence of nano-clay on urea-formaldehyde resins for wood adhesives and its model. Journal of Applied Polymer Science 109(4): 2442-2451.

Lei, H.; Du, G.; Pizzi, A.; Celzard, A.; Fang, Q. 2010. Influence of Nanoclay on Phenol-Formaldehyde and Phenol-Urea-Formaldehyde Resins for Wood Adhesives. Journal of Adhesion Science and Technology 24(8-10): 1567-1576.

Leichti, R.; Falk, R.; Laufenberg, T. 1990a. Prefabricated wood composite I-Beams: A literature review. Wood and Fiber Science 2(1): 62-79.

Leichti, R.; Falk, R.; Laufenberg, T. 1990b. Prefabricated wood I-Joists: An industry overview. Forest Products Journal 40(3): 15-20.

Lisperguer, J.; Rozas, C. 2005. Paneles unidos por canto y contralaminados fabricados con madera juvenil de Eucalyptus nitens. Bosque 26(3): 75-79. 
Mansouri, H.; Pizzi, A.; Leban, J. 2006. Improved water resistance of UF adhesives for plywood by small pMDI additions. Holz als Roh-und Werkstoff 64: 218-220.

Moya, R.; Rodríguez, A.; Vega, J.; Álvarez, V. 2015a. Effects of adding nano-clay (montmorillonite) on performance of polyvinylacetate (PVAc) and urea-formaldehyde (UF) adhesives in Carapa guianensis, a tropical species. International Journal of Adhesion \& Adhesives 59:62-70.

Moya, R.; Rodriguez-Zuñiga A.; Vega-Baudrit, J. 2015b. Effects of adding multiwall carbon-nanotubes (MWCNT) on performance of polyvinyl acetate (PVAc) and urea-formaldehyde (UF) adhesives in tropical timber species. Journal of Nanomaterials Volume 2015, Article ID 895650.

Pirayesh, H.; Khanjanzadeh, H.; Salari, A. 2013. Effect of using walnut/almond shells on the physical, mechanical properties and formaldehyde emission of particleboard. Composites Part B: Engineering 45(1): 858-863.

Pique, T. M.; Pérez, C.J.; Alvarez, V.A.; Vázquez, A. 2013. Water soluble nanocomposite films based on poly (vinyl alcohol) and chemically modified montmorillonites. Journal of Composite Materials 48 (5): 545-553.

Pukánszky, B. 2005. Interfaces and interphases in multicomponent materials: past, present, future. European Polymer Journal 41(4): 645-662.

Serrano, R.; Moya, R. 2011. Procesamiento, uso y mercado de la madera en Costa Rica: aspectos históricos y análisis crítico. Revista Forestal Mesoamericana Kurú 9(21): 12 p.

Schultz, J.; Lavielle, L.; Martin, C. 1987. The role of the interface in carbon fibre-epoxy composites. The Journal of Adhesion 23(1): 45-60.

Shukla, SR.; Pascal, D. 2008. Properties of laminated veneer lumber (LVL) made with low density hardwood species effect of the pressure duration. European Journal of Wood and Wood Products 66: 119-127.

Stoeckel, F.; Konnerth, J.; Gindl, W. 2013. Mechanical properties of adhesives for bonding wood - A review. International Journal of Adhesion and Adhesives 45: 32-41.

Tenorio, C.; Moya, R.; Muñoz, F. 2011. A comparative study on physical and mechanical properties of LVL and plywood panels made of wood from fast growing Gmelina arborea trees. Journal of Wood Science 57(2): 134-139.

Tenorio, C.; Moya, R.; Camacho, D. 2012. Propiedades físico-mecánicas de tableros terciados construidos con especies tropicales de plantaciones para uso estructural. CERNE-Lavras 18(2): 317325 .

Tenorio, C.; Moya, R.; Salas, C.; Berrocal, A. 2016. Evaluation of wood properties from six native species of forest plantations in Costa Rica. Bosque 37(1): 71-84.

Vick, C. 1999. Adhesive bonding of wood materials. Chapter 9. In: Wood Handbook - Wood as an engineering material. USDA Forest Products Staff Eds. General Technical Report. FPL-GTR-113. Madison, WI: U.S. Department of Agriculture, Forest Service, Forest Products Laboratory: 1-24.

Xian, D.; Semple, K. E.; Haghdan, S.; Smith, G. D. 2013. Properties and Wood Bonding Capacity of Nano-clay-Modified Urea and Melamine Formaldehyde Resins. Wood and Fiber Science 45(4): 383-395.

Zhao, L. F.; Liu, Y.; Xu, Z. D.; Zhang, Y. Z.; Zhao, F.; Zhang, S. B. 2011. State of research and trends in development of wood adhesives. Forestry Studies in China 13(4): 321-326. 